\title{
Measurement and Evaluation of Regional Financial Integration in Guangdong, Hong Kong and Macao Based on the Panel Data from 2000 to 2018
}

\author{
Shizhong Xiong ${ }^{1, *}$ Dongxu Yang $^{1}$ Xiaofang Xiong $^{1}$
}

\author{
${ }^{1}$ Department of Accounting, Xinhua College of Sun Yat-Sen University Dongguan, Guangdong, China \\ *Corresponding author. Email: xsz9293@126.com
}

\begin{abstract}
Financial integration is the trend and hub of China's contemporary high-quality economic development and regional financial integration is an important carrier to realize the coordinated and stable development of regional economy and promote financial innovation. Taking the Guangdong-Hong Kong-Macao Greater Bay Area as an investigation object, this paper collects the panel data of 11 cities in the bay area from 2000 to 2018 , and constructs a model of financial integration measurement by using the price method, quantity method and principal component analysis. The empirical results show that with the extension of time, the level of regional financial integration continues to improve, but it is still at a low level and in an urgent need to improve to a certain extent. In view of this prominent problem, relevant policy suggestions are put forward.
\end{abstract}

Keywords: Guangdong-Hong Kong-Macao Greater Bay Area, regional financial integration, measurement, empirical analysis

\section{INTRODUCTION}

Financial integration is not only the trend of highquality economic development in contemporary China, but also an important hub and medium to realize the coordinated and steady development of regional economy and promote financial innovation in the Guangdong-Hong Kong-Macao Greater Bay Area. The financial integration of Guangdong, Hong Kong and Macao includes the international financial center of Hong Kong, the entertainment service center of Macau and the financial technology service and production center of the Pearl River Delta. Due to the heterogeneity of regional conditions, although the three factors are closely linked, they have unique operation modes in the process of financial integration. In the process of regional economic integration, finance plays the role of hub, resource flow matching and regulating regional economic operation, thus becoming the essence of financial integration. Therefore, the systematic study of financial integration in the Guangdong-Hong Kong-Macao Greater Bay Area has important theoretical value and practical significance in promoting regional financial cooperation.

*This paper is the phased research results of the project approved by the Department of Finance of Guangdong Province (Project No.: Z201951).

\section{LITERATURE REVIEW}

Financial integration is not only the focus of attention in China and abroad, but also the focus of the Guangdong-Hong Kong-Macao Greater Bay Area. Many Chinese and overseas scholars have conducted in-depth research on this, mainly focusing on the following aspects of price method, quantity method and principal component analysis.

\section{A. Price method}

Yu et al. (2010), Rein et al. (2010), Raphael et al. (2011) and Wei Qing (2009) et al., measured financial integration based on the parameters of interest rate and stock price, and tested whether economic integration had been achieved or realized.

\section{B. Quantity method}

F-H (Feldstein and Herioka) (1980), Montiel(1994), Anders(2001) and other scholars used the deposit and loan relationship to analyze and return the panel data of developed and developing countries, demonstrating that the more open the capital market is, the stronger the capital liquidity is, and the better the degree of financial integration is. Zhang Yingxi (2007), Wu Lingfang and Huang Meibo (2009), Wei Qing (2010), Wu Xiaoxia and Li Qing(2015), Zhang Feng and Xiao Wendong (2016) discussed the financial integration process based 
on the relationship between savings and loan in southeast Asia, the Pearl River Delta, Yangtze river delta and the Beijing-Tianjin-Hebei Region, and the results show that when the coefficient of deposit and loan decreases, the degree of financial integration is higher and different.

Scholars such as Bayoumi (1990) and Kose et al. (2009) discussed through the consumption quantity smoothing method that in the process of complete financial integration, the correlation coefficient between domestic consumption and domestic output is small, while that between domestic consumption and output of other countries is large.

Lane and Milesi (2003) and Liu Shenglong and Zhang Jie (2009) et al. used the quantitative method of asset ratio (ratio of assets to GDP) to measure financial integration. The greater the value of this index is, the higher the measure of financial integration will be.

\section{Principal component analysis}

Principal component analysis is a method of "analysis-dimensions-factor analysis" by means of SPSS software, which quantifies many indicators into several main indicators and makes them irrelevant, and selects several main components from them to solve the collinearity contradiction among multiple variables and thus improve the analysis effect. Su Chunzi (2018) explored the level of financial integration in East Asia by using the principal component analysis method. The result was that the index of integration fluctuated somewhat, but the level of financial integration gradually improved.

To sum up, by sorting out different literatures on the level of financial integration, it can be concluded that there are more studies on the level of financial integration among countries, the Yangtze River Delta and the Beijing-Tianjin-Hebei region, yet relatively few on the Guangdong-Hong Kong-Macao Greater Bay Area as a whole, with the empirical research at the initial stage.

\section{MODEL CONSTRUCTION AND EMPIRICAL ANALYSIS}

The econometric model of financial integration is constructed and empirical analysis is made.

\section{A. The model of financial integration is constructed based on deposit and loan relationship}

1) Model construction: Based on the F-H (1980) model, the model evolved into:

$$
(\mathrm{I} / \mathrm{GDP})_{i t}=\boldsymbol{\alpha}+\boldsymbol{\beta} *(\mathrm{~S} / \mathrm{GDP})_{i t}+\boldsymbol{\mu}_{\mathrm{it}}
$$

In this formula, i represents the city, $t$ represents the year, and $\mu_{\mathrm{it}}$ represents the error.

2) Data source and variable description: The data are from the wind Database, China Statistical Yearbook (2001-2019), and the statistical yearbook of Hong Kong and Macao (2001-2019). In this paper, the panel data of nine cities in the Pearl River Delta (guangzhou, shenzhen, Zhuhai, Foshan, Dongguan, Zhongshan, Jiangmen, Huizhou and Zhaoqing) in the GuangdongHong Kong-Macao Greater Bay Area and Hong Kong and Macao SAR cities from 2001 to 2019 are selected as the research object. The explained variable is expressed by the investment efficiency (I/GDP), while the variable is expressed by the savings efficiency (S/GDP). S "savings" is local GDP- $\left(\mathrm{C}_{\mathrm{p}}+\mathrm{C}_{\mathrm{g}}\right)$, that is, local output minus private and government consumption; the investment is the total amount of capital formed in each region.

$\beta$ represents the liquidity of capital, meaning that the larger its value is, the smaller the integration level is and vice versa.

3) Empirical analysis of integration of GuangdongHong Kong-Macao Greater Bay Area: Considering the heterogeneity, irregularity and unit root of the panel data in the region, the variables were processed by difference method to reduce the volatility of investment efficiency and savings efficiency, and then regressed. The results are shown in "Table I".

TABLE I. INTEGRATION RESUlts OF GUANGDONG-HONG KONG-MACAO GREATER BAy AREA

\begin{tabular}{|c|c|c|}
\hline & Pearl River Delta & Guangdong-Hong Kong-Macao Greater Bay Area \\
\hline $\boldsymbol{\beta}$ & $0.00350^{* * *}$ & $0.00170^{* * *}$ \\
\hline $\boldsymbol{R}^{2}$ & $0.384^{*}$ & $0.573^{* * *}$ \\
\hline $\boldsymbol{A}-\boldsymbol{R}^{2}$ & 0.0413 & 0.1364 \\
\hline $\boldsymbol{p}$ & 0.0346 & 0.0158 \\
\hline
\end{tabular}

Note: ***, **, and * respectively, represent significant levels of $1 \%, 5 \%$ and $10 \%$

According to the analysis in "Table I," the following results are obtained.
- The correlation coefficient of investment and savings efficiency in the Pearl River Delta is positive and significant at the $10 \%$ level, while 
the level of financial integration is not high and the capital elements cannot flow completely freely; the coefficient of coefficient in Guangdong-Hong Kong-Macao Greater Bay Area is 0.573 , which is significant at the $1 \%$ level, but the level of integration is also low.

- Judging from the $\beta$ coefficient, the capital liquidity of the Pearl River Delta is strong and that in the Guangdong-Hong Kong-Macao Greater Bay Area is low. However, on the whole, the integration of the Pearl River Delta and the Guangdong-Hong Kong-Macao Greater Bay Area is estimated very low, with a low coupling degree of the financial market, which has great room for improvement.

\section{B. Constructing the financial integration model based on the quantitative method}

1) Model construction: On the basis of $\mathrm{Y}=\mathrm{C}+\mathrm{I}+\mathrm{G}+\mathrm{NX}$, it is assumed that the utility of economic individuals is the same and the same. When the integration of financial market is achieved among economies, each economy realizes the consumption smoothness through the flow of factor capital in the region. The model evolves as follows:

$$
\mathrm{C}_{\mathrm{it}}=\alpha+\beta(\mathrm{Y}-\mathrm{I}-\mathrm{G}){ }_{\text {it }}+\gamma \mathrm{C}_{\text {at }}+\varepsilon_{\mathrm{it}}
$$

In this formula, $\mathrm{i}$ represents the economy city, $\mathrm{t}$ represents the year and $\varepsilon_{\text {it }}$ represents the error.

2) Data source and variable description: The data source is the same as above. The explained variable is denoted by $\mathrm{C}_{\mathrm{it}}$ as consumption of economy $\mathrm{i}$ at time $\mathrm{t}$; the variables are denoted by (Y-I-G)it and Cat, (Y-I-G)it represents consumption resources provided by economy I at time $\mathrm{t} ; \mathrm{C}_{\mathrm{at}}$ represents consumption of other economies at time $\mathrm{t}$; I represents investment of economy I; and $\mathrm{G}$ represents government consumption of economy i. $\beta$ represents the relationship between an economy's consumption and its output; $\gamma$ represents the relationship between the consumption between one economy and the other. The larger the $\beta$ value is, the larger the $\gamma_{i s}$, reflecting that the more developed the market development of the economy city is, the level of financial integration is, and vice versa.

3) Empirical analysis of integration of GuangdongHong Kong-Macao Greater Bay Area: Considering the heterogeneity, non-stationarity and unit root of the panel data, the variables were processed by difference method to reduce the volatility, and then regressive results were obtained (see "Table II").

TABLE II. FINANCIAL INTEGRATION RESUlTS OF GUANGDONG-HONG KONG-MACAO GREATER BAY AREA

\begin{tabular}{|c|c|c|}
\hline & Pearl River Delta & Guangdong-Hong Kong-Macao Greater Bay Area \\
\hline $\boldsymbol{\alpha}$ & 4.321506 & 7.044692 \\
\hline $\boldsymbol{\beta}$ & $0.3974812^{* * *}$ & $0.350731 * * *$ \\
\hline $\boldsymbol{\gamma}$ & $0.4460715 * * *$ & $0.473128 * * *$ \\
\hline $\mathbf{R}^{2}$ & 0.5346 & 0.5251 \\
\hline $\mathbf{p}$ & 0.000000 & 0.00000 \\
\hline
\end{tabular}

According to the analysis of "Table II", the following results are obtained:

- The correlation coefficient of consumption output in the Pearl River Delta and the Guangdong-Hong Kong-Macao Greater Bay Area is positive, with small difference, and it is significant at the $1 \%$ level, which indicates that the financial market coupling degree is low and the level of market integration is not high. However, the consumption coefficient of the Pearl River Delta and the Guangdong-Hong Kong-Macao Greater Bay Area is significant at $1 \%$ level, which is 0.446 and 0.473 respectively, indicating that the market integration level of the Guangdong-Hong Kong-Macao Greater Bay Area is relatively high, while that of the Pearl River Delta is relatively low.
Note: ***,**, and * respectively, represent significant levels of $1 \%, 5 \%$ and $10 \%$

- The empirical results show that, according to the rule of "the smaller the $\beta$ value, the larger the $Y$ value, the degree of financial integration in the Guangdong-Hong Kong-Macao Greater Bay Area is relatively high, while that in the Pearl River Delta is relatively low. However, on the whole, the integration level of the Pearl River Delta and the Guangdong-Hong Kong-Macao Greater Bay Area is very low, the coupling degree of financial market is low, and the regional capital flow is small, which is consistent with the conclusion of the deposit and loan relationship model analysis. 
C. Constructing the financial integration measurement model based on principal component analysis

1) Constructing the principal component analysis model of financial integration: Based on the model of Su Chunzi (2018), the following model is constructed:

$$
Y_{i}=\mu_{\mathrm{i} 1} \mathrm{X}_{1}+\mu_{\mathrm{i} 2} \mathrm{X}_{2}+\mu_{\mathrm{i} 3} \mathrm{X}_{3}+\cdots \mu_{\mathrm{in}} \mathrm{X}_{\mathrm{n}}
$$

In this formula, $\mathrm{X}_{\mathrm{n}}$ is the original variable, $\mathrm{Y}_{\mathrm{i}}$ is the main component, $\mathrm{n}$ is the number, $\mu_{\text {in }}$ is the number $\mathrm{i}$ principal component $\mathrm{Yi}$ and the coefficient of the number $\mathrm{n}$ original variable $\mathrm{Xn}$.

2) Constructing the financial integration level indicator system: Based on the availability of data, indicators such as stock trading volume, capital stock, foreign direct investment, foreign capital inflow, bank loans and trade balance were selected, and the ratios of these indicators to GDP were calculated respectively. $\mathrm{X} 1$ represents the proportion of stock transactions, $\mathrm{X} 2$ represents the proportion of foreign investment, $\mathrm{X} 3$ represents the proportion of bank loans, X4 represents the proportion of capital stock, X5 represents the proportion of foreign capital inflows, and X6 represents the proportion of trade balance.

3) Principal component analysis of financial integration level: Considering the influence of time trend on principal component, the original data were processed, tested and analyzed in a standardized way.

a) Correlation test: According to the theory of principal component analysis, the premise of dimensionality reduction by use of the principal component analysis is that there is a strong correlation between the original indexes. According to the data shown in "Table III", except for X5, the absolute values of the coefficients are all greater than 0.5, indicating that each index has a strong correlation with each other and meets the conditions of major component analysis.

TABLE III. INDEX CORRELATION COEFFICIENT MATRIX

\begin{tabular}{|c|c|c|c|c|c|c|c|}
\hline & & X1 & X2 & X3 & X4 & X5 & X6 \\
\hline \multirow{6}{*}{$\begin{array}{c}\text { Correlation } \\
\quad\langle b r\rangle\end{array}$} & $\mathrm{X} 1$ & 1.000 & 0.510 & 0.607 & 0.550 & -0.293 & -0.535 \\
\hline & $\mathrm{X} 2$ & 0.510 & 1.000 & 0.396 & 0.027 & -0.160 & -0.438 \\
\hline & X3 & 0.607 & 0.396 & 1.000 & 0.531 & -0.160 & -0.562 \\
\hline & $\mathrm{X} 4$ & 0.550 & 0.027 & 0.531 & 1.000 & -0.109 & 0.024 \\
\hline & X5 & -0.293 & -0.160 & -0.160 & -0.109 & 1.000 & 0.187 \\
\hline & X6 & -0.535 & -0.438 & -0.562 & 0.024 & 0.187 & 1.000 \\
\hline
\end{tabular}

Data source: obtained from the collation and calculation based on the SPSS software.

b) Communalities test: "Table IV" shows the extraction of common factors from the original variances. From the column of "extraction", it can be seen that the common variance of the extracted characteristic values contains the effective information of the common degree. With the only largest effective information loss of X5, the others are all above $60 \%$, and the largest is above $87 \%$, which meets the conditions of the main component analysis.

TABLE IV. COMMUNALITIES TEST

\begin{tabular}{|l|l|l|}
\hline & Initial value & Extraction \\
\hline $\boldsymbol{X} \mathbf{1}$ & 1 & 0.761 \\
\hline $\boldsymbol{X} \mathbf{2}$ & 1 & 0.620 \\
\hline $\boldsymbol{X} \mathbf{3}$ & 1 & 0.770 \\
\hline $\boldsymbol{X} \mathbf{4}$ & 1 & 0.872 \\
\hline $\boldsymbol{X} \mathbf{5}$ & 1 & 0.161 \\
\hline $\boldsymbol{X} 6$ & 1 & 0.741 \\
\hline
\end{tabular}

c) Extraction of principal components: The principal component analysis is based on the eigenvalue and the cumulative contribution rate of variance. Here, the major component with the eigenvalue greater than 1 and the cumulative contribution rate of variance greater than $80 \%$ is selected as the principal component and the index to analyze its influence. "Table V" shows that the two principal components contain most of the effective information of the six indicators, and the two main components are sufficient to explain the changes in the degree of financial integration in Guangdong, Hong Kong and Macao, so as to achieve the goal of dimension reduction. 
TABLE V. FACTOR CHARACTERISTIC VALUE, VARIANCE AND CUMULATIVE CONTRIBUTION RATE

\begin{tabular}{|c|l|l|l|l|l|l|}
\hline \multirow{2}{*}{ Component } & \multicolumn{3}{|c|}{ Initial Eigenvalue } & \multicolumn{3}{c|}{ Extracting the Sum of Squares and Load } \\
\cline { 2 - 7 } & Summation & $\begin{array}{c}\text { Percentage of } \\
\text { the Variance }\end{array}$ & $\begin{array}{c}\text { Accumulative } \\
\text { Percentage }\end{array}$ & Summation & $\begin{array}{c}\text { Percentage of } \\
\text { the Variance }\end{array}$ & $\begin{array}{c}\text { Accumulative } \\
\text { Percentage }\end{array}$ \\
\hline $\mathbf{1}$ & 2.661 & 54.346 & 54.346 & 2.611 & 544.346 & 54.346 \\
\hline $\mathbf{2}$ & 1.244 & 25.734 & 80.080 & 1.244 & 25.734 & \\
\hline $\mathbf{3}$ & 0.721 & 9.352 & 89.432 & & & \\
\hline $\mathbf{4}$ & 0.493 & 5.878 & 95.310 & & & \\
\hline $\mathbf{5}$ & 0.273 & 3.219 & 98.529 & & & \\
\hline $\mathbf{6}$ & 0.108 & 1.471 & 100.000 & & & \\
\hline
\end{tabular}

d) Function and meaning of principal component: The principal component load matrix reflects the correlation between the principal component and the original variables - if the absolute value of the coefficient is large, the correlation is strong. According to "Table VI", except for X5, the coefficients of other variables are all greater than 0.5 , and the correlation is also strong; X1, X2, X3, X4 represent the degrees of financial market integration, and X6 represents the degree of trade integration.

TABLE VI. LOAD MATRIX

\begin{tabular}{|l|l|l|}
\hline \multirow{2}{*}{} & \multicolumn{2}{|c|}{ Component } \\
\cline { 2 - 3 } $\boldsymbol{X} \mathbf{1}$ & $\mathbf{2}$ \\
\hline $\boldsymbol{X} \mathbf{2}$ & 0.814 & 0.281 \\
\hline $\boldsymbol{X} \mathbf{3}$ & 0.574 & -0.539 \\
\hline $\boldsymbol{4}$ & 0.875 & 0.065 \\
\hline $\boldsymbol{X} \mathbf{5}$ & 0.575 & 0.736 \\
\hline $\boldsymbol{X} \mathbf{6}$ & -0.393 & 0.081 \\
\hline
\end{tabular}

The eigenvector of each principal component, which is the expression coefficient of the principal component, is obtained by dividing the load vector of each principal component by the arithmetic square root of the eigenvalue of each principal component (see "Table VII").

TABLE VII. EXPRESSION COEFFICIENTS OF PRINCIPAL COMPONENTS

\begin{tabular}{|l|l|l|}
\hline \multirow{2}{*}{} & \multicolumn{2}{|c|}{$\begin{array}{c}\text { Expression coefficients of principal } \\
\text { components }\end{array}$} \\
\cline { 2 - 3 } & $\begin{array}{c}\text { Principal } \\
\text { component 1 }\end{array}$ & $\begin{array}{c}\text { Principal } \\
\text { component } 2\end{array}$ \\
\hline $\boldsymbol{X} \mathbf{1}$ & 0.499 & 0.252 \\
\hline $\boldsymbol{X} \mathbf{2}$ & 0.352 & -0.483 \\
\hline $\boldsymbol{X} \mathbf{3}$ & 0.536 & 0.058 \\
\hline $\boldsymbol{X} \mathbf{4}$ & 0.352 & 0.662 \\
\hline $\boldsymbol{X} \mathbf{5}$ & -0.241 & 0.073 \\
\hline $\boldsymbol{X} \mathbf{6}$ & -0.397 & 0.509 \\
\hline
\end{tabular}

The expressions of Y1, Y2 are as follows:

$$
\begin{aligned}
\mathrm{Y} 1 & =0.499 * \mathrm{X} 1+0.352 * \mathrm{X} 2+0.536 * \mathrm{X} 3 \\
& +0.352 * \mathrm{X} 4-0.241 * \mathrm{X} 5-0.397 * \mathrm{X} 6 \\
\mathrm{Y} 2 & =0.252 * \mathrm{X} 1-0.483 * \mathrm{X} 2+0.058 * \mathrm{X} 3 \\
& +0.662 * \mathrm{X} 4+0.0 .073 * \mathrm{X} 5+0.509 * \mathrm{X} 6
\end{aligned}
$$

e) Comprehensive score: According to the principle of principal component analysis, each principal component is given different weight. The weight of the principal component 1 is 0.681 , and the weight of main component 2 is 0.319 . The composite score is the weighted average of each major component and is sorted by time, as shown in "Table VIII".

The formula for the total score is as follows:

$\mathrm{Y}=0.681$ *the score of principal component $1+0.319$ * the score of principal component 2

TABLE VIII. THE FINANCIAL INTEGRATION OF HONG KONG, MACAO AND THE PEARL RIVER DELTA

\begin{tabular}{|l|l|l|l|}
\hline Region & Hong Kong & Macao & $\begin{array}{c}\text { the Pearl } \\
\text { River Delta }\end{array}$ \\
\hline 2000 & 0.42820 & -1.08351 & 0.31825 \\
\hline 2001 & 0.26226 & -1.21013 & -0.00296 \\
\hline 2002 & 0.16944 & -1.27027 & -0.02649 \\
\hline 2003 & 0.22913 & -1.30490 & -0.00749 \\
\hline 2004 & 0.20283 & -1.36424 & 0.07567 \\
\hline 2005 & 0.20768 & -1.46907 & -0.04885 \\
\hline 2006 & 0.46448 & -1.51773 & -0.08122 \\
\hline 2007 & 1.10995 & -1.50362 & 0.43689 \\
\hline 2008 & 1.00230 & -1.50436 & 0.03613 \\
\hline 2009 & 1.11225 & -1.55832 & 0.51958 \\
\hline 2010 & 1.39060 & -1.64878 & 0.67122 \\
\hline 2011 & 1.42676 & -1.67391 & 0.46291 \\
\hline 2012 & 0.86827 & -1.69786 & 0.41888 \\
\hline 2013 & 1.42365 & -1.71552 & 0.59866 \\
\hline 2014 & 1.58971 & -1.62558 & 0.81516 \\
\hline 2015 & 1.68784 & -1.43851 & 1.46458 \\
\hline 2016 & 1.03146 & -1.34290 & 1.01178 \\
\hline 2017 & 1.40524 & -1.40385 & 1.11870 \\
\hline 2018 & 1.99235 & -1.37173 & 1.67100 \\
\hline & & & \\
\hline
\end{tabular}


According to the analysis in "Table VIII", the following results are obtained.

From the comprehensive score of the three regions, namely, the degree of financial integration, the higher the score is, the higher the degree of financial integration is. Although financial integration fluctuates, it continues to improve over time. From 2000 to 2002, the degree of financial integration declined. From 2003 to 2007 , the degree of financial integration developed rapidly. After the recovery, the degree of financial integration gradually deepened. Due to the financial crisis in 2008, the degree of financial integration has decreased compared with that in 2007. From 2010 to 2018, the financial integration degree of Hong Kong reached its peak at 1.99235, and the Pearl River Delta reached 1.671, still in some distance with Hong Kong. The number of Macau also climbed from -1.64879 to 1.37173 , reflecting that for all the low degree, Macao did improve its financial integration.

\section{Conclusion}

To sum up, based on the panel data of 11 cities in the Guangdong-Hong Kong-Macao Greater Bay Area from 2000 to 2018, this paper uses the methods of price, quantity and principal component analysis to construct different models to measure the level or degree of financial integration. The empirical results show that the financial integration in the bay area is still at a low level, and it is in urgent need of effective support and incentives from government policies to build a regional financial coupling mechanism, give play to the complementary functions of financial elements, and improve the space of financial integration.

Through the analysis of financial integration, it provides useful practical experience for the economic development of Guangdong, Hong Kong, Macao and Greater Bay Area. Firstly, with the construction framework agreement of the Guangdong-Hong KongMacao Greater Bay Area as the core, it is necessary to understand and make use of the law of financial integration to build an effective operation mechanism of financial cooperation between the three regions. Secondly, based on the financial structural supply-side reform, efforts should be made to coordinate the guidance of the supply of factors and enhance the complementary functions of financial factors. Third, it is necessary to take Hong Kong international finance as the center to build a new pattern of financial radiation in Hong Kong, financial development in Macao and multi-directional financial opening in the Pearl River Delta. Fourth, it is necessary to take intergovernmental cooperation, policy support and institutional innovation as hubs to achieve long-term coupling of regional finance, improve the level of financial integration, and promote coordinated, stable and high-quality development of regional economy.

\section{References}

[1] Zhang Yingxi. The Analysis of Regional Financial Development and Integration [J]. Journal of Central University of Finance \& Economics, 2007, (5): 33-37. (in Chinese)

[2] Cui Yuansen. Empirical research on financial integration and economic growth in China [J]. Shanghai Finance, 2007, (2): 917. (in Chinese)

[3] Wu Lingfang, Huang Meibo. East Asian financial integration: demonstrative analysis basing on capital flow [J]. Special Zone Economy, 2009, (9): 18-20. (in Chinese)

[4] Liu Shenglong, Zhang Jie. The Impacts on Economic Growth of Financial Integration [J]. Nankai economic research, 2009, (3): 73-86 (in Chinese)

[5] Wei Qing. Status Quo of Financial Integration in Yangtze River Delta - an Analysis Based on Bank Loan Prices [J]. Economic Forum, 2009, (11): 95-97. (in Chinese)

[6] Wei Qing. The Status Quo of Financial Integration in Yangtze River Delta - an Analysis Based on the Relationship Between Deposit and Loan in Banks [J]. Journal of Industria Technological Economics, 2010, (1): 151-154. (in Chinese)

[7] Wu Xiaoxia, Li Qing. Measurement and evaluation of financial integration process in Beijing-Tianjin-Hebei region $[\mathrm{J}]$. Social Sciences in Guangdong, 2015, (5): 31-40. (in Chinese)

[8] Zhang Feng, Xiao Wendong. Measurement and Evaluation of Financial Integration in Beijing-Tianjin-Hebei Region [J]. Seeker, 2016, (7): 95-99. (in Chinese)

[9] Su Chunzi. Research on the Economic Effects of East Asian Financial Integration [D]. Doctoral Dissertation, Liaoning University, 2018: 76-93. (in Chinese)

[10] Feldstein, Herioka. Domestic Saving and International Capital Flows [J]. The Economic Journal, 1980, 90(358): 314-329.

[11] Peter J, Montiel. Capital mobility in Developing Countries: Some Measurement Issues and Empirical Estimates [J]. The World Bank Economic Review, 1994, 8 (3): 311-350.

[12] Anders I. Financial Liberalization, Foreign Aid, and capital mobility: Evidence from 90 Developing Countries [J]. Journa of International Financial Markets, Institutions and Money, 2001, 11(3): 3094-338.

[13] Lane P R and Milesi-Ferretti. International Financial Integration [C].Washington: IMF Third Annual Research Conference, 2003: 82-113.

[14] Kose, M. A., Prasad, E. S., Terroes, M. E. Does Financial Globalization Promote Risk Sharing? [J]. Journal of Development Economics, 2009, 89 (2): 258-270.

[15] Yu I M, Fung K P, Tam C S. Assessing Financial Market Integration in Asia-Equity Markets [J]. Journal of Banking and Finance, 2010, 34 (12): 2874-2885.

[16] Rein W, Ebner A, Borys M. A Factor Analysis Approach to Measuring European Loan and Bond Market Integration [J]. Journal of Banking and Finance, 2010, 35 (4): 1011-1025.

[17] Raphael E, Prasad A, Williams O. Regional Financial Integration in the GCC [J]. Emerging Markets Review, 2011 (12): $354-370$

[18] Bayoumi T. Financial Integration and Real Activity. Studies in Macroeconomics [M]. Manchester: Manchester University Press, 1997. 